\title{
RAPID MAPPING OF FORESTED LANDSLIDE FROM ULTRA-HIGH RESOLUTION UNMANNED AERIAL VEHICLE DATA
}

\author{
R. Comert ${ }^{1, *}$, U. Avdan ${ }^{1}$, T. Gorum ${ }^{2}$ \\ ${ }^{1}$ Institute of Earth and Space Sciences, Anadolu University, Eskisehir - (rcomert, uavdan)@anadolu.edu.tr \\ ${ }^{2}$ Department of Geography, Istanbul University, Istanbul, Turkey - tgorum@ gmail.com
}

KEY WORDS: UAV, landslide, object-based image analysis, Bartın, Black Sea Region, rapid mapping

\begin{abstract}
:
The Black Sea Region is one of the most landslide prone area due to the high slope gradients, heavy rainfall and highly weathered hillslope material conditions in Turkey. The landslide occurrences in this region are mainly controlled by the hydro-climatic conditions and anthropogenic activities. Rapid regional landslide inventory mapping after a major event is main difficulties encountered in this densely vegetated region. However, landslide inventories are first step and necessary for susceptibility assessment since considering the principle that the past is the key to the future thus, future landslides will be more likely to occur under similar conditions, which have led to past and present instability. In this respect, it is important to apply rapid mapping techniques to create regional landslide inventory maps of the area. This study presents the preliminary results of the semi-automated mapping of landslides from unmanned aerial vehicles (UAV) with object-based image analysis (OBIA) approach. Within the scope of the study, ultra-high resolution aerial photographs were taken with fixed wing UAV system on Aug 17, 2017 in the landslide zones which are triggered by the prolonged heavy rainfall event on August 12-13, 2016 at Bartın Kurucaşile province. $10 \mathrm{~cm}$ resolution orthomosaic and Digital Surface Model (DSM) data of the area were produced by processing the obtained photographs. A test area was selected from the overall research area and semi-automatic landslide detection was performed by applying object-based image analysis. OBIA has been implemented in three steps: image segmentation, image object metric calculation and classification. The accuracy of the resulting maps is assessed by comparisons with expert based landslide inventory map of the area. As a result of the comparison, $80 \%$ of the 240 landslides in the area were detected correctly.
\end{abstract}

\section{INTRODUCTION}

Landslides are one of the major natural disasters that cause loss of human life, environmental damage and economic loss (Chen et al. 2014). Landslide susceptibility, risk and hazard analysis, which are useful for land planning and natural risk management, play an important role in reducing these losses and damages (Catani et al. 2013). Fast generation of landslide inventory maps after a major event is necessary both to carry out such analysis and rapid damage assessments (Chen et al. 2014; Martha et al. 2012).

Remote sensing data enables more opportunity for landslide inventory mapping. Traditional method based on the visual interpretation one of the well-known methods. It was applied different type of remotely sensed data such as aerial images (Van Westen and Getahun 2003), medium resolution satellite images (Petley et al. 2002), and high resolution satellite images (Nichol et al. 2006). Although, visual interpretation provides much more reliable information, it is time consuming due to the long manual processing (Van Westen et al. 2008). Another method of landslide inventory mapping is pixel based classification methods. Unsupervised classification (Borghuis et al. 2007) and supervised classification (Borghuis et al. 2007; Danneels et al. 2007) methods were successfully applied to the satellite image derived event inventory mapping. Object-based image analysis (OBIA) has become more popular in the field of remote sensing, after increasing the number of satellite systems that offer much higher spatial resolution. While pixel based classification uses only spectral information of pixel, object based approach use spectral, spatial, geometric and morphometric feature of image objects (Martha et al. 2010). In many studies, OBIA was used to create landslide inventory (Aksoy and Ercanoglu 2012; Blaschke et al. 2014; Chen et al. 2017; Lahousse et al. 2011; Li et al. 2015; Lu et al. 2011; Martha et al. 2010; Martha et al. 2011; Stumpf and Kerle 2011).

Last decades, a new remote sensing platform that called Unmanned Aerial Vehicle (UAV) was started to use land survey applications. UAV platforms give several advantages such as low cost, repeatable data collecting, ultra - high resolution images and fly in cloudy weather over the aerial and satellite based platform when the study area is small (Lelong et al. 2008). UAV systems was used monitoring landslide in several studies (Lindner et al. 2016; Lucieer et al. 2014; Niethammer et al. 2009), There is limited studies that focus on the landslide mapping with UAV systems. (Rau et al. 2011; Shi and Liu 2015). Therefore, it is necessary to investigate the feasibility of using UAV systems in landslide mapping in different regions.

Black sea region is one of the landslide prone area in Turkey. Because of the high slope gradients and densely vegetated condition terrestrial survey is difficult in this region. Also, due to heavy rainy weather, cloud problems can arise when a new satellite image is captured after a major landslide event. High clouds do not prevent with image capture with the UAV systems. It can be used as a useful system for rapid mapping of landslides in this region in terms of collecting data without traveling over the land.

The purpose of this study is to investigate the performance of unmanned aerial vehicles in the mapping of forested landslides. In the scope of the study, ultra -high resolution aerial image of study area was obtained with UAV systems. Then orthomosaic, Digital Surface Model (DSM) and Digital Terrain Model (DTM) data was generated using aerial images and flight information. OBIA was performed for mapping landslide using these data and derivatives. The final obtained results based on the OBIA was 
assessed by comparisons with expert based landslide inventory map.

\section{METARIAL}

\subsection{Study Area}

The study area is Kurucasile district, in Bartin Province of Western Black Sea Region of Turkey (Figure 1). Because of the heavy rainfall, rapid snowmelt, stream erosion, high slope gradients and highly weathered hillslope material conditions, It is one of the most landslide prone area in Turkey (Ercanoglu and Gokceoglu 2004; Erener and Düzgün 2013). Hydro-climatic conditions and anthropogenic activities control the landslide occurrence in this region.

There was a very heavy rainfall event in Bartin province On 1213 August 2016. It was determined that the amount of rainfall for two days on Kurucasile is about $188 \mathrm{~mm}$ according to the data obtained from the radar images. This amount is more than two times higher than the August average for many years (19502015) at this area. Heavy rainfall has triggered flood and landslide events. Therefore, there has been a great deal of damage to the house, workplace, roads and bridges (Bulut 2016). The area selected for this study is a region where there are many landslides affected by this event.

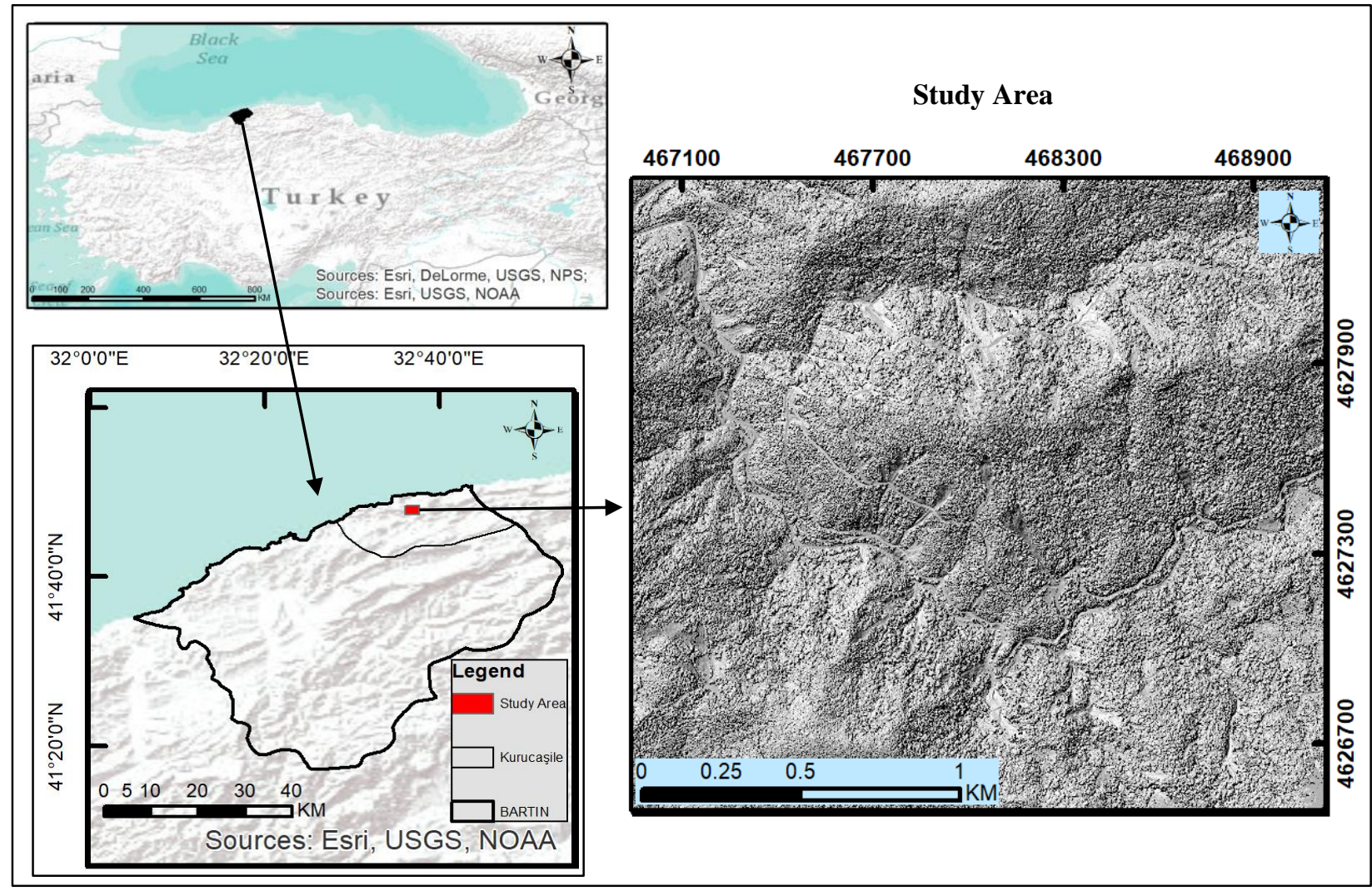

Figure 1. Kurucasile study area in Bartın Province of Western Black See Region at Turkey

\subsection{Specification of Used UAV Systems}

In this study, fixed wing UAV system (Sensefly eBee Plus) was used for aerial image collections. The system has 20 megapixel RGB digital camera (S.O.D.A) which was developed for professional photogrammetric drone mapping. Drone is controlled with Emotion - 3 flight management software that used for flight planning, simulation, flight control and preparation of images for post-processing. It also has a RTK/PPK systems which allows to precise positioning with horizontal accuracy about $3 \mathrm{~cm}$ and vertical accuracy about $5 \mathrm{~cm}$. Drone cruise speed changes between $40 \mathrm{~km} / \mathrm{h}$ to $110 \mathrm{~km} / \mathrm{h}$. It has up to $45 \mathrm{~km} / \mathrm{h}$ wind resistance. UAV systems is $1.1 \mathrm{~kg}$ with $110 \mathrm{~cm}$ wing span. Its flight time is nearly one hour for one flight.

\subsection{Aerial Image Collection}

Two different flights were performed to obtain aerial images of all study area with fixed wing UAV system on 17 August 2017. The flights planned $70 \%$ lateral overlap and $75 \%$ longitudinal overlap with $5 \mathrm{~cm}$ ground sample distance (GSD). Images was taken nearly 212 meters altitude above grounds. Totally 793 images were collected.

\subsection{Data Processing}

The images collected with the UAV system is processed in the pix4d Mapper software. As a result of the data processing, a 10 $\mathrm{cm}$ resolution orthomosaic and DSM of the study area were produced. Also, $50 \mathrm{~cm}$ DTM was generated for study area.

\section{METHODS}

The process steps applied in this study are summarized in Figure 2. Information about aerial image collection and data processing is given section 2.3 and section 2.4. This section focuses on OBIA which consists of image segmentation and classification. 


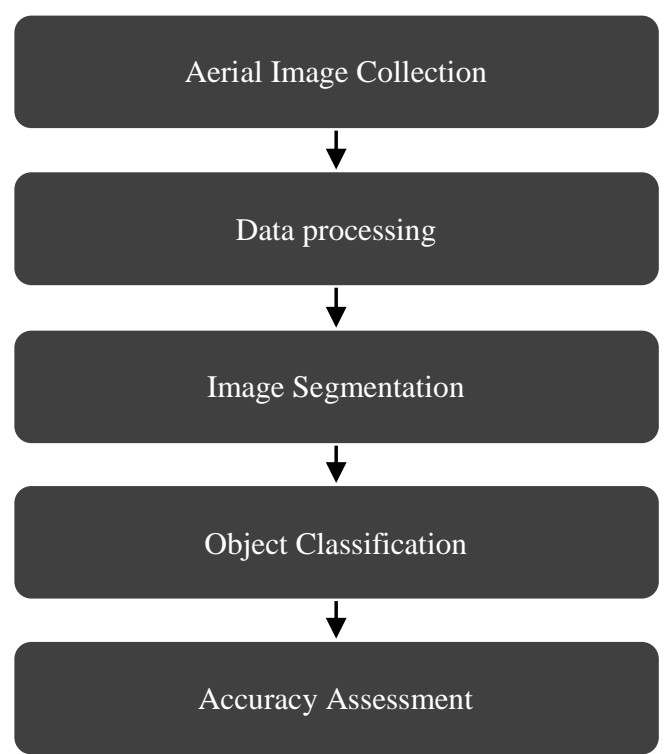

Figure 2. Process steps applied in this study

\subsection{Object Based Image Analysis (OBIA)}

OBIA is an image analysis method that provides effective and automatic methods for very high resolution images in remote sensing applications. Unlike pixel-based image analysis, it involves analysing the spectral, textural, spatial and topological relationships of images objects (Lang 2008). It consists of two staged approaches which are image segmentation and object classifications (Baatz et al. 2008).

\subsubsection{Image Segmentation}

Aim of the image segmentation is generating homogenous image objects from pixel or existing image objects. Several methods have been developed for remote sensing applications over the decades (Dey et al. 2010). Multi resolution segmentation (MRS) is widely used method in landslide detection studies (Hölbling et al. 2012; Martha et al. 2010; Stumpf and Kerle 2011). Therefore, MRS was preferred in this study.

MRS starts one-pixel level and it composes image objects by combining neighbouring pixels according to a certain spectral and geometric homogeneity criterion. Some parameters such as scale, shape, compactness and layer weight must be specified by the user before segmentation to determine the optimum image objects. The most important parameter is scale which directly affect the image object size. While the large scale parameter creates large image objects, the small scale parameter creates small objects (Benz et al. 2004; Martha et al. 2010). Different methods were applied to determine the optimum scale parameter for landslide studies. Trial - error method is one of the used methods (Blaschke et al. 2014; Dou et al. 2015; Martha et al. 2010). Also, automatic methods such as Estimation Scale Parameter (ESP) tool (Drăguţ et al. 2014) was used to determine optimum parameters (Eisank et al. 2014; Stumpf and Kerle 2011). In this study trial - error method was used to find optimum parameters for MRS.

\subsubsection{Object Classification}

Classification of similar image objects is completed after the segmentation phase. Object classification can be done using machine learning algorithms (Chen et al. 2017; Dou et al. 2015; Stumpf and Kerle 2011) or rule based classifications (Lahousse et al. 2011; Rau et al. 2011). In this study rule based classification was applied to the image objects.

The spectral bands of orthomosaic and DSM data were used to developed rule sets for classifications. The study area is densely covered with vegetation such as tree and grass. Normalized Difference Vegetation Index (NDVI) was mainly used for separation of vegetation from landslide candidates (Lahousse et al. 2011). Due to the fact that the camera used in this study don't has near infrared band, Excess Green Index (EGI) (Woebbecke et al. 1995) was used to separate the vegetation (Eq. (1)).

$$
\mathrm{EGI}=2 * \text { Green }- \text { Red }- \text { Blue }
$$

Some places in the study area are shadowed. Brightness value, which is calculated as the sum of objects means in visible band $\left(\bar{c}_{i(v i s)}\right)$ divided by number of corresponding bands $\left(n_{(v i s)}\right)$, was used for separation of images objects that belongs to these places from landslide candidates. Equation (2) presents calculation of Brightness (B) value.

$$
\mathrm{B}=\frac{1}{\mathrm{n}_{\mathrm{vis}}} \sum_{\mathrm{i}=1}^{\mathrm{n}_{\mathrm{vis}}} \overline{\mathrm{c}}_{\mathrm{i} \text { (vis) }}
$$

The slope data which was created from DSM has been utilized for the separation of the roads, few flat areas and river beds. Also, extreme images objects between roads and forest was separated using image object width and slope data.

\subsection{Accuracy Assessment}

Evaluated of the object based images analysis results for landslide mapping and landslide inventory map for study area was created by expert opinion. The success of the method was determined by dividing true positive landslides areas into total expert based mapped landslides areas.

\section{RESULT}

\subsection{Results of Segmentation}

Red, Green, Blue (RGB) and slope layers were used input data for MRS. UAV flight was made nearly one year later after the landslide event. Therefore, forest roads and landslides have approximately the same spectral properties. When the image segmentation was performed only using Red, Green, Blue (RGB) layers, these areas could be segmented in same images objects. Slope layer was added at the segmentation to prevent this situation, because the roads have lower slope value than landslides.

In this study single scale segmentation was used. Several parameters were tried to determine optimum parameters for MRS. After trial - error steps optimum parameters were determined as scale 50 , shape 0.3 , compactness 0.5 . Also equal weight was given all layers. Using these parameters small images objects were created. After classification steps, landslides candidates were merged to generate exact landslides.

\subsection{Results of Object Classification}

In classification steps firstly, vegetation, roads, rivers beds, few flat area and extreme image objects was separated from landslide candidates. Then landslide candidates were merged. 
Table 1. shows the threshold value that was used rule sets for separation value of land use objects from landslide candidates. EGI generally gives useful results on vegetation if it is green. EGI value higher than 1.09 was assigned to vegetation class. Slope layer is more useful parameters for roads, flat area and river beds. Because these areas have lower slope value $(\leq 30 \%)$ than landslide area. Shadow areas were eliminated using Brightness value $(\leq 60)$. Because of the using slope layer in segmentation steps, some extreme image object was created. These extreme objects are caused by sudden elevation changes between the road edges and the trees. They have extreme slope value. slope and object width value was used to elimination of these kind of image objects.

\begin{tabular}{|l|l|l|}
\hline Parameters & $\begin{array}{l}\text { Threshold } \\
\text { Value }\end{array}$ & Attended Class \\
\hline EGI & $\geq 1.09$ & Vegetation \\
\hline Slope & $\leq 30 \%$ & $\begin{array}{l}\text { Roads, few flats } \\
\text { area, river beds }\end{array}$ \\
\hline Brightness & $\leq 60$ & Shadow \\
\hline $\begin{array}{l}\text { Slope } \\
\text { Width }\end{array}$ & $\begin{array}{l}\geq 200 \% \\
\leq 46\end{array}$ & $\begin{array}{l}\text { Extreme image } \\
\text { objects }\end{array}$ \\
\hline
\end{tabular}

Table 1. Threshold value of parameters which was used in rule set to eliminates images objects from landslides.

After elimination of different land cover class from landslide candidates, all candidates were merged to create final landslides. Figure 3 shows the obtained landslides using OBIA. While Red coloured polygons indicate the landslides which were extracted by the methodology applied in this study. Blue bordered polygons show the landslides that generated by experts.

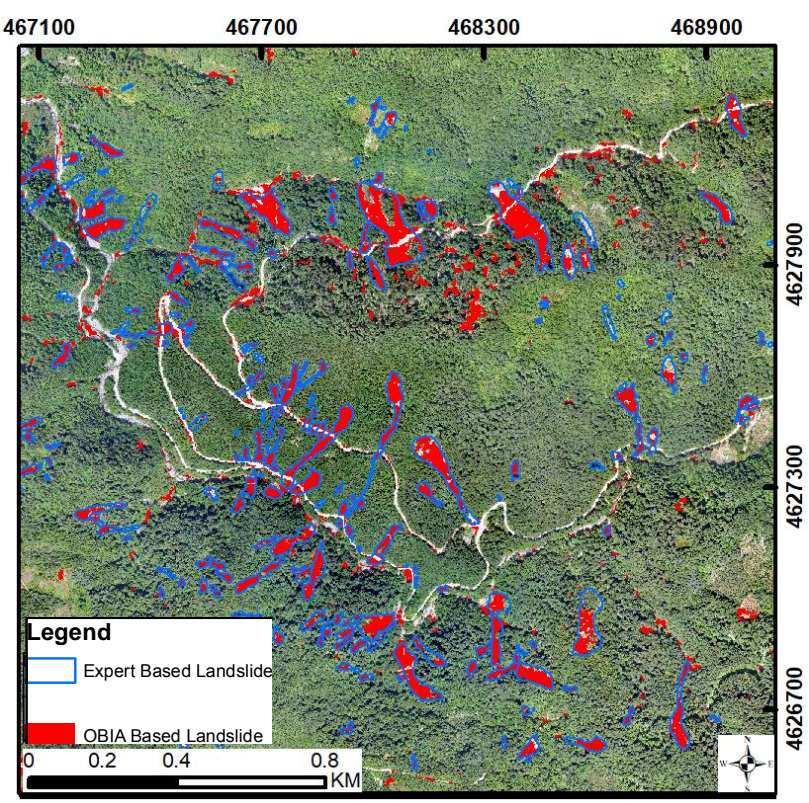

Figure 3. Results landslides maps, red coloured polygon shows the OBIA based landslides, blue bordered polygons show experts based landslides.

\subsection{Accuracy Assessment Results}

The landslide inventory map was created an expert. There are 240 landslides in the study area. 192 of the 240 landslides were detected as true positive landslide by applied methodology. This value equals $80 \%$ of total landslides.

\section{DISCUSION}

Rapid data collections are very important for landslide inventory mapping studies using remote sensing techniques. Because recent occurred landslides give more brightness value than other land use types due to clearing of related areas. Data collection of this study was performed nearly one year later the landslide event. This situation effected the segmentation steps.

Our study area is densely vegetated area. These kind of areas were easily eliminated from landslide area using NDVI indices at satellite images based studies. EGI that was used in this study can be an alternative to NDVI. However, this index has been found to give good results when the vegetation is green.

Some of the landslides in the shadows and under the trees could not be extracted applied methodology (Figure 4 (a) and Figure 4 (b)). The shadow has been a problem in this study as it is in many remote sensing applications (Hölbling et al. 2012; Rau et al. 2011). Also, some non - landslide area near the roads was extracted as landslides (Figure 4 (c)). Many areas especially near the roads detected as landslides like figure 4 (c).

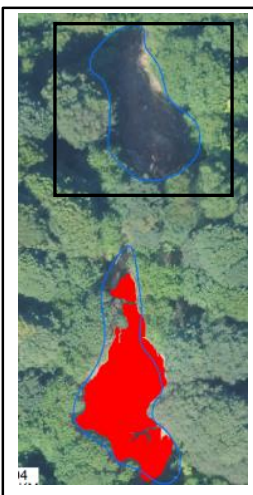

(a) shadow

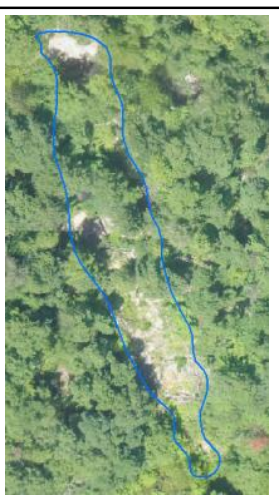

(b) Landslides under trees

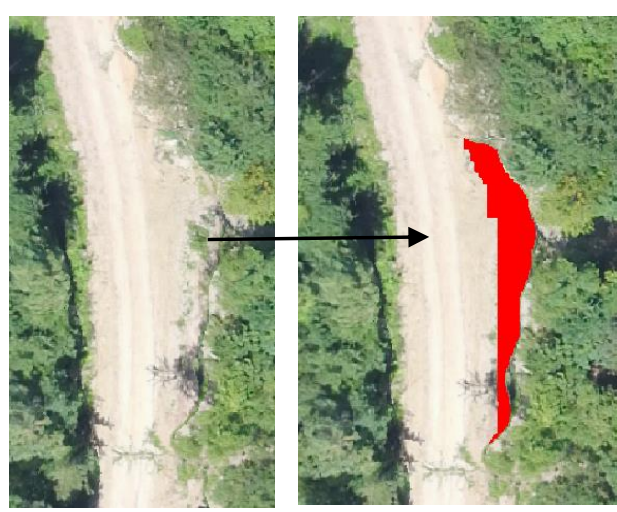

(c) non - landslide area

Figure 4. landslide mapping problems (a): Shadow problem, (b): vegetation cover problem, (c): falsely extracted landslides.

An advantages of UAV system, it gives both spectral information and elevation information for the study area. It is possible to create elevation data such as DSM and DTM using overlapped images. Derivatives of DSM such as slope very important parameters for landslides studies. In this studies slope were used to eliminate many land use types. 
Study area don't include complex land use types such as buildings, different types of vegetation or bare soil area. The performance of the UAV system should be tested on more complex study areas.

\section{CONCLUSION}

Rapid landslide inventory mapping is important for landslide prone areas. UAV systems can be a solution for such areas which offres ultra-high resolution spatial data like orthomosaics and DSMs. This study presents the preliminary results of a continuing project which is semi-automated mapping of landslides from unmanned aerial vehicles (UAV) with object-based image analysis (OBIA) approach. According to obtained results forest landslides mapped with accuracy of $80 \%$. But some nonlandslides area was extracted as landslides. Only five parameters were used for developing classification rule sets. In future studies, the applied method will be developed by including textural parameters and shape parameters and morphological parameters of landslide such as terrain curvature, flow direction. Automatic methods for image segmentation will be applied the data set. Also, machine learning algorithm will be used for classification steps.

\section{ACKNOWLEDGEMENTS}

This study was supported by Anadolu University Scientific Research Projects Commission under the grant number 1608F607. The authors would like to thank İsmail Bulut from General Directorate of Combating Desertification and Erosion for his valuable suggestions on the site-selection.

\section{REFERENCES}

Aksoy, B., \& Ercanoglu, M. (2012). Landslide identification and classification by object-based image analysis and fuzzy logic: An example from the Azdavay region (Kastamonu, Turkey). Computers \& Geosciences, 38, 87-98

Baatz, M., Hoffmann, C., \& Willhauck, G. (2008). Progressing from object-based to object-oriented image analysis. ObjectBased Image Analysis (pp. 29-42): Springer

Benz, U.C., Hofmann, P., Willhauck, G., Lingenfelder, I., \& Heynen, M. (2004). Multi-resolution, object-oriented fuzzy analysis of remote sensing data for GIS-ready information. Isprs Journal of Photogrammetry and Remote Sensing, 58, 239-258

Blaschke, T., Feizizadeh, B., \& Holbling, D. (2014). ObjectBased Image Analysis and Digital Terrain Analysis for Locating Landslides in the Urmia Lake Basin, Iran. Ieee Journal of Selected Topics in Applied Earth Observations and Remote Sensing, 7, 4806-4817

Borghuis, A., Chang, K., \& Lee, H. (2007). Comparison between automated and manual mapping of typhoon-triggered landslides from SPOT-5 imagery. International Journal of Remote Sensing, $28,1843-1856$

Bulut, İ. (2016). Bartın Merkez, Amasra ve Kurucaşile İlçeleri Sınırları İçerisinde 12-13 Ağustos 2016 Tarihinde Yaşanan Sel Afeti Sunumu. In: T.C. Orman ve Su İşleri Bakanlığı, Çölleşme ve Erozyonla Mücadele Genel Müdürlüğü

Catani, F., Lagomarsino, D., Segoni, S., \& Tofani, V. (2013). Landslide susceptibility estimation by random forests technique: sensitivity and scaling issues. Natural Hazards and Earth System Sciences, 13, 2815-2831

Chen, T., Trinder, J.C., \& Niu, R. (2017). Object-Oriented Landslide Mapping Using ZY-3 Satellite Imagery, Random Forest and Mathematical Morphology, for the Three-Gorges Reservoir, China. Remote Sensing, 9, 333

Chen, W.T., Li, X.J., Wang, Y.X., Chen, G., \& Liu, S.W. (2014). Forested landslide detection using LiDAR data and the random forest algorithm: A case study of the Three Gorges, China. Remote Sensing of Environment, 152, 291-301

Danneels, G., Pirard, E., \& Havenith, H.-B. (2007). Automatic landslide detection from remote sensing images using supervised classification methods. In, Geoscience and Remote Sensing Symposium, 2007. IGARSS 2007. IEEE International (pp. 30143017): IEEE

Dey, V., Zhang, Y., \& Zhong, M. (2010). A review on image segmentation techniques with remote sensing perspective

Dou, J., Chang, K.T., Chen, S.S., Yunus, A.P., Liu, J.K., Xia, H., \& Zhu, Z.F. (2015). Automatic Case-Based Reasoning Approach for Landslide Detection: Integration of Object-Oriented Image Analysis and a Genetic Algorithm. Remote Sensing, 7, 43184342

Drăguţ, L., Csillik, O., Eisank, C., \& Tiede, D. (2014). Automated parameterisation for multi-scale image segmentation on multiple layers. Isprs Journal of Photogrammetry and Remote Sensing, 88, 119-127

Eisank, C., Hölbling, D., Friedl, B., Chen, Y., \& Chang, K. (2014). Expert knowledge for object-based landslide mapping in Taiwan. S East Eur J Earth Obs Geomat Spec Issue: GEOBIA, 347-350

Ercanoglu, M., \& Gokceoglu, C. (2004). Use of fuzzy relations to produce landslide susceptibility map of a landslide prone area (West Black Sea Region, Turkey). Engineering Geology, 75, 229-250

Erener, A., \& Düzgün, H.S. (2013). A regional scale quantitative risk assessment for landslides: case of Kumluca watershed in Bartin, Turkey. Landslides, 10, 55-73

Hölbling, D., Füreder, P., Antolini, F., Cigna, F., Casagli, N., \& Lang, S. (2012). A semi-automated object-based approach for landslide detection validated by persistent scatterer interferometry measures and landslide inventories. Remote Sensing, 4, 1310-1336

Lahousse, T., Chang, K.T., \& Lin, Y.H. (2011). Landslide mapping with multi-scale object-based image analysis - a case study in the Baichi watershed, Taiwan. Natural Hazards and Earth System Sciences, 11, 2715-2726

Lang, S. (2008). Object-based image analysis for remote sensing applications: modeling reality-dealing with complexity. Objectbased image analysis (pp. 3-27): Springer

Lelong, C.C., Burger, P., Jubelin, G., Roux, B., Labbé, S., \& Baret, F. (2008). Assessment of unmanned aerial vehicles imagery for quantitative monitoring of wheat crop in small plots. Sensors, 8, 3557-3585

Li, X.J., Cheng, X.W., Chen, W.T., Chen, G., \& Liu, S.W. (2015). Identification of Forested Landslides Using LiDar Data, Object-based Image Analysis, and Machine Learning Algorithms. Remote Sensing, 7, 9705-9726 
Lindner, G., Schraml, K., Mansberger, R., \& Hübl, J. (2016). UAV monitoring and documentation of a large landslide. Applied Geomatics, 8, 1-11

Lu, P., Stumpf, A., Kerle, N., \& Casagli, N. (2011). Objectoriented change detection for landslide rapid mapping. Ieee Geoscience and Remote Sensing Letters, 8, 701-705

Lucieer, A., Jong, S.M.d., \& Turner, D. (2014). Mapping landslide displacements using Structure from Motion (SfM) and image correlation of multi-temporal UAV photography. Progress in Physical Geography, 38, 97-116

Martha, T.R., Kerle, N., Jetten, V., van Westen, C.J., \& Kumar, K.V. (2010). Characterising spectral, spatial and morphometric properties of landslides for semi-automatic detection using object-oriented methods. Geomorphology, 116, 24-36

Martha, T.R., Kerle, N., van Westen, C.J., Jetten, V., \& Kumar, K.V. (2011). Segment Optimization and Data-Driven Thresholding for Knowledge-Based Landslide Detection by Object-Based Image Analysis. Ieee Transactions on Geoscience and Remote Sensing, 49, 4928-4943

Martha, T.R., Kerle, N., van Westen, C.J., Jetten, V., \& Kumar, K.V. (2012). Object-oriented analysis of multi-temporal panchromatic images for creation of historical landslide inventories. Isprs Journal of Photogrammetry and Remote Sensing, 67, 105-119

Nichol, J.E., Shaker, A., \& Wong, M.-S. (2006). Application of high-resolution stereo satellite images to detailed landslide hazard assessment. Geomorphology, 76, 68-75

Niethammer, U., Rothmund, S., \& Joswig, M. (2009). UAVbased remote sensing of the slow-moving landslide Super-Sauze.
In, Proceedings of the International Conference on Landslide Processes: from geomorpholgic mapping to dynamic modelling, Strasbourg, CERG Editions (pp. 69-74)

Petley, D.N., Crick, W.D., \& Hart, A. (2002). The use of satellite imagery in landslide studies in high mountain areas. In, Proceedings of the Asian conference on remote sensing

Rau, J., Jhan, J., Lo, C., \& Lin, Y. (2011). Landslide mapping using imagery acquired by a fixed-wing UAV. Int. Arch. Photogramm. Remote Sens. Spat. Inf. Sci, 38, 1-C22

Shi, B., \& Liu, C. (2015). UAV for landslide mapping and deformation analysis. In, International Conference on Intelligent Earth Observing and Applications 2015 (p. 98080P): International Society for Optics and Photonics

Stumpf, A., \& Kerle, N. (2011). Object-oriented mapping of landslides using Random Forests. Remote Sensing of Environment, 115, 2564-2577

Van Westen, C., \& Getahun, F.L. (2003). Analyzing the evolution of the Tessina landslide using aerial photographs and digital elevation models. Geomorphology, 54, 77-89

Van Westen, C.J., Castellanos, E., \& Kuriakose, S.L. (2008). Spatial data for landslide susceptibility, hazard, and vulnerability assessment: an overview. Engineering Geology, 102, 112-131

Woebbecke, D.M., Meyer, G.E., Von Bargen, K., \& Mortensen, D. (1995). Color indices for weed identification under various soil, residue, and lighting conditions. Transactions of the ASAE, $38,259-269$ 